\title{
Memórias da repressão e da resistência: um olhar comparado entre Brasil e Argentina ${ }^{1}$
}

\author{
Maria Guiomar da Cunha Frota \\ Professora Associada na Escola de Ciência da Informação da UFMG \\ Doutora em Sociologia pelo IUPERJ \\ E-mail: frotaguiomar@yahoo.com.br
}

\begin{abstract}
RESUMO:
Diante da necessidade social de publicização de informações relativas a violações de direitos humanos e de gestão e disseminação das memórias da repressão e da resistência às ditaduras militares no contexto do Cone Sul, este trabalho tem por objetivo apresentar resultados parciais de uma pesquisa empirica sobre duas temáticas: arquivos da repressão e da resistência no Brasil e na Argentina; e a justiça transicional e publicização de informações sobre mortos e desaparecidos no Brasil. Para tanto, empreendeu-se pesquisa bibliográfica tanto para caracterizar a inserção das temáticas relativas à memória nas ciências sociais e na ciência da informação, quanto para compreender os elementos fundamentais que permeiam o conceito de justiça de transição, empreendeu-se também estudo de caso no Arquivo Nacional, no contexto brasileiro, e no Arquivo Nacional da Memória, em âmbito argentino. Exaltase a necessidade de políticas públicas e sociais que fomentem o acesso as informações relativas a violações de direitos humanos armazenadas nos arquivos citados, e destaca-se a necessidade do empreendimento de investigações científicas no âmbito da Arquivologia, Biblioteconomia e Museologia para potencialização da organização, disseminação e gestão desses estoques informacionais.
\end{abstract}

Palavras-chave: Justiça de transição. Registros da memória. Direitos humanos.

\begin{abstract}
:
On the social need to publicize information regarding human rights violations and the management and dissemination process on memories of repression and resistance to military dictatorships in the context of the Southern Cone, this study aims to present partial results of an empirical research on two themes: archives of repression and resistance in Brazil and Argentina, and the transitional justice and the dissemination of information about the dead and disappeared in Brazil. For this, was undertaken a bibliographical research both to characterize the insertion of the themes related to memory in the social sciences and in the information science, as well as to understand the fundamental elements that permeate the concept of transitional justice. Was also carried out a case study in the National Archives, in the Brazilian context, and in the National Archives of Memory, on Argentina. There is a need for public and social policies that foster access to the information on human rights violations in the cited archives, and it is necessary to carry out scientific research in the field of archivology, library science and museology to enhance the organization, dissemination and management process of these informational stocks.
\end{abstract}

Key-words: Transitional justice. Memories records. Human rights.

\footnotetext{
${ }^{1}$ Palestra apresentada na abertura do VI Colóquio de Pesquisa em Ciência da Informação. A Informação e Cidadania: o olhar da Ciência da Informação através da Memória, UFRN, 3/05/2016.
} 


\section{INTRODUÇÃO}

No campo das ciências humanas é fundamental que o pesquisador apresente seu lugar de fala, explicite de início aos leitores ou ouvintes suas motivações e também algo de sua biografia. Assim o ouvinte poderá compreender melhor os argumentos, a forma de problematizar e avaliar, numa perspectiva construtivista e crítica, não só o conteúdo e os resultados, mas o processo de pesquisa como um todo.

Sempre trabalhei com a temática dos direitos humanos, esse é o abrigo para todos os diversos temas que pesquiso e também a fonte das minhas opções políticas e de militância social. As reflexões teóricas e sistematizações de pesquisas empíricas que hoje compartilho com vocês são parte de um projeto "Memórias da repressão e da resistência no Cone Sul" que teve duas fortes motivações para a sua elaboração.

Em 2012, estive na Argentina, durante um congresso para apresentar um trabalho sobre a Corte Interamericana de Direitos Humanos, conheci então o Parque da Memória, a visita me tocou profundamente. Trata-se de um parque que expõe obras de arte que se referem aos mortos e desaparecidos, vítimas da ditadura militar argentina (1979-1983). ${ }^{2}$

Outra motivação fundamental foi o fato de lecionar e pesquisar em uma Escola (a Escola de Ciência da Informação da Universidade Federal de Minas Gerais) que abriga os cursos de graduação em Biblioteconomia, Arquivologia e Museologia e de pós-graduação em Ciência da Informação. Assim queria muito elaborar um projeto de pesquisa que pudesse também subsidiar uma formação acadêmica mais política e humanista focada no tema da memória. Elaborei então um programa de pesquisa amplo sobre as memórias da repressão no Cone Sul.

O que pretendo apresentar para vocês também é parte da pesquisa comparada entre Brasil e Argentina que estou realizando no âmbito do meu estágio pós-doutoral (desenvolvido em 2015, na Argentina, junto ao Núcleo de Estudos sobre Memória e em 2016, no PPGH da UNIRIO).

Eu organizei essa exposição em três partes: na primeira parte situo o tema das memórias da repressão e da resistência e da publicização das informações sobre violações aos direitos humanos, no campo mais amplo das Ciências Sociais e mais específico da Ciência da Informação. Na segunda parte apresento alguns referenciais

\footnotetext{
${ }^{2}$ Sobre o parque ver http://parquedelamemoria.org.ar/
} 
teóricos centrais para compreensão do tema mobilizados no contexto latino americano que tratam dos seguintes aspectos: a) justiça de transição, b) políticas de memória e c) os arquivos da repressão e da resistência. E finalmente, na terceira, apresento alguns resultados parciais das pesquisas empíricas relativos a dois temas: a) arquivos da repressão e da resistência no Brasil e na Argentina e b) justiça transicional e publicitação de informações sobre mortos e desaparecidos no Brasil.

\section{BREVE INSERÇÃO DO TEMA DA MEMÓRIA NAS CIÊNCIAS SOCIAIS E NA CIÊNCIA DA INFORMAÇÃO}

Considero que as ciências sociais se encontram diante de um grande desafio - o de pensar as memórias da repressão e da resistência no contexto atual. Contexto no qual intensas disputas em torno da representação do golpe militar de 1964 estão no centro da acirrada luta política pelo poder, no qual memórias sociais concorrentes e em conflito invadem o espaço público e as redes sociais. A imagem imediata e lastimável que tenho em mente é a homenagem do deputado Bolsonaro ao Coronel Ustra, realizada durante a declaração de voto na Câmara dos Deputados, favorável ao impedimento da presidenta Dilma Russef, no dia 17/04/2016. O Coronel Ustra foi um torturador da ditadura militar, reconhecido pública e judicialmente como tal, que chefiou o DOI-CODI do exército de São Paulo, entre 1970 e 1974, durante seu comando cerca de 50 pessoas foram assassinadas ou desapareceram e 500 foram torturadas. Diversas imagens subsequentes invadiram as redes sociais em protesto contra a homenagem, tratavam-se de fotos, documentos e testemunhos, memórias sociais das violações de direitos humanos, durante a ditadura, expressas pelas próprias vítimas, sobreviventes ou por amigos, familiares e organizações de defesa de direitos, que recuperam essas vozes, memórias de outras memórias. Infelizmente também foram expressas manifestações de apoio ao discurso em defesa do torturador. Fatos como esse demostram a relevância das ciências sociais se debruçarem sobre o tema das memórias da repressão.

No campo das ciências sociais o tema das violações aos direitos humanos e da memória social, ganha relevância especialmente nos contextos do pós-guerra e 
mais especificamente da vigência de longos regimes totalitários e ditatoriais. $\mathrm{Na}$ Europa destacaram-se os trabalhos, hoje clássicos, escritos por Hannah Arendt. ${ }^{3}$

$\mathrm{Na}$ América Latina, especialmente após a restauração de regimes democráticos, ocorrida em vários países, entre as décadas de 1970 e 1980, tem início pesquisas sobre as temáticas da cidadania e dos novos movimentos sociais. Essas pesquisas eram motivadas, por um lado, pela constatação de extremas desigualdades sociais, achatamento salarial, desemprego, crescimento da miséria e, por outro lado, pela constatação do intenso cerceamento aos direitos políticos e civis e da violência extrema contra as classes populares, decorrentes da cultura e das políticas e práticas repressivas dos regimes ditatoriais na região (Paraguai, Uruguai, Brasil, Argentina e Chile). Paralelamente o tema da memória também ganhava relevância motivado pela intensa demanda política pelo resgate das memórias da repressão e das violações aos direitos humanos, ocorridas durante as ditaduras militares e pela instauração dos processos de justiça restaurativa em diversos países na região.

A Ciência da Informação, no Brasil, acompanha essa tendência do campo mais amplo. Nas décadas de 1970 e 80, criam-se novas linhas de pesquisa, voltadas para os temas da cidadania, dos movimentos sociais e da memória da ditadura e da resistência. Não apresentarei aqui um levantamento exaustivo, mas alguns exemplos que ilustram as formas de inserção da Ciência da Informação nas referidas temáticas:

1‥ A tese de Ana Cardoso Andrade, defendida em 1989, sobre os Centros de Documentação e de Comunicação Popular (CDCPs) que funcionaram nas décadas de 1970-80, que podem ser definidos como:

\begin{abstract}
espaços que tiveram um papel fundamental tanto na produção e organização de informação relativa à atuação e a memória dos movimentos sociais, quanto na realização de estratégias de educação e de comunicação popular [...] os centros, em sua fase inicial, concentraram sua atuação em atividades de resistência à ditadura e de memória dos movimentos sociais, num segundo momento, incorporaram também às suas práticas a resistência à indústria cultural, ou seja, à hegemonia dos meios de comunicação de massa, estimulando o resgate da cultura popular. (ANDRADE, 1989, p. 114).
\end{abstract}

2‥ A tese de Icléia Thiesen - Memória Institucional, defendida em 1996 e publicada em 2013, foi um trabalho pioneiro. A autoria dialoga com relevantes correntes teóricas sobre memória, na filosofia, na sociologia e na história para refletir

\footnotetext{
${ }^{3}$ Ver ARENDT, Hanna. Entre o passado e o futuro 1979; ARENDT, H. O julgamento de Eischmann em Jerusalém, 1999.
} 
sobre a memória Institucional e a Institucionalização da Ciência da Informação. Recentemente, Icléia desenvolveu um programa de pesquisa essencial para o desenvolvimento do tema das memórias da repressão na Ciência da Informação; resultados importantes dessa pesquisa foram publicados no livro "Documentos sensíveis".

3․ Na ANCIB, dois grupos, englobam trabalhos sobre memórias ou temas correlatos, como a lei de acesso à informação, o GT Memoria Social e Informação e o GT Políticas de Informação.

4․ $\mathrm{Na}$ ECI/UFMG o tema das memórias compõe uma das três linhas de pesquisa do Programa de Pós-Graduação em Ciência da Informação. Outras duas iniciativas são o grupo de pesquisa, Memórias da repressão e da resistência no Cone Sul, que eu criei e coordeno, desde de 2014 e a publicação do livro, Lei de acesso à informação, coordenada pela professora Maria Aparecida Moura.

\section{JUSTIÇA DE TRANSIÇÃO, POLÍTICAS DE MEMÓRIA E ARQUIVOS DA REPRESSÃO: UMA PERSPECTIVA LATINO-AMERICANA}

As possibilidades de problematizar o tema das memórias da repressão e da resistência são muitas assim, nessa parte da exposição, apresento algumas referências que considero essenciais e que abordam: a justiça de transição, as políticas de memória e os arquivos da repressão e da resistência.

\section{a) Justiça de transição}

Inicialmente considero que é importante compreender como políticas de memória, verdade e justiça se interacionam em distintos contextos e não adotar como pressuposto que se tratam de processos lineares, simultâneos e que culminariam em um estágio ideal em termos de justiça transicional.

A justiça transicional consiste num conjunto de procedimentos que têm como objetivos centrais, ressalta-se que:

o (re)estabelecimento do Estado de direito, o reconhecimento das violações aos direitos humanos -suas vítimas e autores- e a promoção das possibilidades de aprofundamento democrático, pela justiça, verdade, reparação, memória e reforma das instituições (ABRÃO; GENRO, 2012, p.33). 
As diversas práticas e procedimentos de justiça transicional foram classificados por esses autores em quatro tipos, a saber:

a) apuração e responsabilização dos crimes ocorridos nas ditaduras ou conflitos civis para o (re)estabelecimento do estado de direito; (...)b) criação das comissões de verdade, que são os instrumentos de investigação e informação sobre os abusos chaves de períodos do passado caracterizados pela censura e pela baixa transparência informacional (...), c) programas e comissões de reparação às vítimas, (...), d) reformas institucionais dos sistemas de segurança, para adequá-los ao respeito à cidadania e a integridade social, (...), e) políticas públicas de memória com práticas institucionais que implementem memoriais e outros espaços capazes de resignificar a história do país (ABRÃO e GENRO, 2012, p. 34-43).

Na América Latina os procedimentos de justiça transicional têm adquirido formas e percursos distintos em cada país e essas distinções estão correlacionadas aos processos transicionais dos regimes ditatoriais para os democráticos. No QUADRO I, a seguir, apresento de forma sintética, essas distinções:

Quadro 1 - Justiça transicional: Brasil e Argentina

\begin{tabular}{|c|c|c|}
\hline & Brasil & Argentina \\
\hline Transição & $\begin{array}{c}\text { Por pacto- lenta, gradual, } \\
\text { medidas de liberalização } \\
\text { pontuais. Resulta numa eleição } \\
\text { indireta para presidente definida } \\
\text { pela conciliação de forças dos } \\
\text { dois espectros, do ditatorial e do } \\
\text { democrático. }\end{array}$ & $\begin{array}{l}\text { Por colapso do regime- conjunto de } \\
\text { fatores: guerra das Malvinas, } \\
\text { denúncias de violações aos direitos } \\
\text { humanos. Resulta eleição direta } \\
\text { (Alfonsín) }\end{array}$ \\
\hline $\begin{array}{l}\text { Justiça } \\
\text { transicional }\end{array}$ & $\begin{array}{c}\text { Comissão Especial sobre Mortes } \\
\text { e desaparecidos (Lei } \\
9.140 / 1995) . \\
\text { Comissão de Anistia (lei } \\
\text { 19.599/2002). } \\
\text { Comissão Nacional da Verdade } \\
\text { (lei 12.528/2011) }\end{array}$ & $\begin{array}{c}\text { Comissão Nacional sobre } \\
\text { desaparecimentos forçados- } \\
\text { CONADEP (1983-84). } \\
\text { Juízos aos comandantes das Juntas } \\
\text { Militares (1985). } \\
\text { Decretos indulto (89-90) Lei de Ponto } \\
\text { Final (1986) } \\
\text { Políticas de memória e juízos pela } \\
\text { verdade (2003-2015). }\end{array}$ \\
\hline
\end{tabular}

Fonte: Adaptado de ABRÃO e GENRO (2012); CRENZEL (2008); FELD e FRANCO (2015); O'DONNEL e REIS (1988); TORELLY(2012).

A transição argentina é definida como transição por colapso do regime, por uma conjunção de fatores, como a crise econômica e principalmente a derrota na guerra das Malvinas. O governo militar não teve força política suficiente para impor 
condições para a transição, desse modo as reinvindicações por justiça e verdade, antes restritas aos organismos de direitos humanos, alcançaram a sociedade de modo mais amplo que no Brasil e foram incorporadas no âmbito da primeira disputa eleitoral. A Argentina assim iniciou políticas governamentais de verdade (de apuração do desaparecimento de pessoas através da CONADEP) e de justiça (julgamento dos comandantes que compunham as juntas militares) no início do período transicional durante o governo Alfonsín, em 1983-84. Posteriormente o percurso argentino apresentou recuos- notadamente com as denominadas leis de impunidade (Lei ponto final, em 1986 e decretos de indulto em 1989 e 1990) - e avanços -notadamente a partir de diversas políticas implementadas de 2003 a 2015, pelos governos kirchneristas.

A transição brasileira é caracteriza como uma transição lenta e gradual marcada por medidas pontuais liberalizantes implementadas a partir de meados da década de 1970, como eleições diretas para os governos estaduais, reforma partidária e lei de anistia. Essa transição culminou numa eleição indireta para presidente definida pela conciliação de forças representantes dos dois espectros, do ditatorial e do democrático. Este formato da transição inviabilizou a inclusão das reivindicações por verdade e justiça na agenda dos primeiros governos eleitos por via direta, pelo voto. Embora grupos de familiares e organizações de direitos humanos tenham lutado por um formato de anistia que possibilitasse a volta dos anistiados e a soltura dos presos políticos, o resultado foi uma lei restrita e que incluía a anistia para agentes das forças repressivas responsáveis pelas violações de direitos humanos, torturas, mortes e desaparições. A temática do direito à verdade e a justiça não alcançou a opinião pública mais ampla. ${ }^{4}$

Assim o Brasil iniciou tardiamente políticas no campo da justiça transicional. Quando se adota 1984, como início da redemocratização, observa-se que as primeiras políticas governamentais só foram iniciadas onze anos depois, em 1995, com a instauração da Comissão de Mortos e Desaparecidos Políticos. Em 2002 iniciaram-se as políticas restaurativas com o amplo trabalho da Comissão de Anistia que recebeu cerca de 70.000 processos. Em 2011 se instalou uma comissão de apuração das violações e de indicação dos responsáveis, a Comissão Nacional da Verdade, mas

\footnotetext{
4 Para percursos da justiça transicional na Argentina ver RABOTNIKOF (2007), CRENZEL (2008), BESSE e ESCOLAR (2012); FRANCO e LEVÍ (2007), FILIPINI,2011. Para os percursos no Brasil ver: ABRÃO e GENRO (2012), TORELLY(2012), FROTA (2014), SILVA(2014).
} 
sem mandato de julgamento dos violadores. O relatório final da comissão foi divulgado em 2015.

Essa alternância entre momentos de resistência/avanço e de acomodação/ retrocesso, em termos de justiça transicional, conforme Alexandra BRITO (2002), são resultantes da correlação de forças em disputa em cada país, envolvendo o chefe do executivo, os partidos e o poder legislativo, os militares, o poder judiciário e as organizações de direitos humanos. A autora interpreta ainda que as lutas por verdade e justiça, mesmo apresentando percursos distintos, nos países do Cone Sul, são parte da política e do imaginário social e permanecem com instâncias de conflito em aberto.

\title{
b) Políticas de memória
}

Rabotnikof (2007) considera que, apesar da inegável centralidade que o tema da memória adquiriu no espaço público (mais especificamente na Argentina), é necessário avançar na formulação de conceitos e reflexões sobre o tema. Assim estrutura uma definição na qual distingue memórias da política e políticas de memória:

\begin{abstract}
Por memorias da política nos referimos a las formas y narraciones a través de las cuales los que fueran contemporáneos de un periodo construyen el recuerdo de ese pasado político, narrando sus experiencias y articulan, de manera polémica, pasado, presente y futuro. Y también a las imágenes de la política que aquellos que no fueron contemporáneos construyen de ese pasado a partir de los testimonios, recuerdos, documentos. O sea, a las memorias de otras memorias. Por políticas de memoria, en cambio, aludimos a las formas de gestionar o de lidiar con ese pasado, a través de medidas de justicia retroactiva, juicios históricos-políticos, instauración de conmemoraciones, fechas y lugares, apropiaciones simbólicas de distinto tipo. Pero por políticas de la memoria también se hace referencia aquí a 'las grandes ofertas de sentido temporal', o las narrativas más generales, que proponen marcos institucionales (y están implícitas en ellos), construyen temporalidades diferentes y de ese modo contribuyen a marcar continuidades y rupturas (RABOTNIKOF, 2007, p. 260-261).
\end{abstract}

Besse e Escolar (2012) especificam os conceitos elaborados por RABOTINIKOF e propõem que as políticas de memória remetem a três acepções, a saber:

- Política como controvérsia- "relações de força e sentido em torno da simbolização do passado, do ordenamento do presente e da orientação ao futuro" (BESSE; ESCOLAR, 2012, págs. 901); trata-se sobretudo de uma "dimensão simbólica ordenadora de heterogeneidades, na qual atuam fortemente as memórias da política” (BESSE; ESCOLAR, 2012, págs. 901). 
Política como gestão- "políticas públicas, processos ou cursos de ação institucional, como planos, programas e projetos que configuram as agendas de governo, tais como empreendimentos de musealização e recuperação de centros clandestinos de detenção" (BESSE; ESCOLAR, 2012, págs. 902).

- Política como narrativa, instância "do sentido, da língua e do desejo, inscrita no campo da crítica transdisciplinar" (BESSE; ESCOLAR, 2012, págs. 902).

Nessa exposição abordarei as políticas de memória enfocando principalmente as instituições de memória e mais especificamente os arquivos. Assim é importante especificar os conceitos relativos aos arquivos da repressão e da resistência.

\section{c) Os arquivos da repressão e da resistência}

A partir das concepções sobre políticas de memória elaboradas por Rabotinikof (2007) e Besse e Escolar (2012), considero pertinente analisar os arquivos como instituições:

- $\quad$ atravessadas por relações de força e de disputas entre grupos sociais em torno da simbolização do passado;

- resultantes de decisões no plano da gestão das políticas públicas, decisões estas que refletem relações de força entre instituições no interior do estado e com as organizações não governamentais;

- cujas formas de ordenamento e gestão expressam decisões de ordem narrativa em relação às relações passado, presente e futuro.

O trabalho de Karababikian (2006) propõe uma delimitação ampla dos arquivos correlacionados às suas instituições produtoras:

I. archivos generados por instituciones de seguridad del Estado, con fines represivos, II. archivos generados por organizaciones (o personas) de la sociedad civil, con fines de defensa, oposición, denuncia o resistencia y III. archivos generados por comisiones investigadoras, con fines de conocimiento de la verdad, procesos judiciales y acciones reparatorias (KARABABIKIAN, 2006, p. 13).

Uma ressalva importante apontada por Karababikian (2006) é que a guarda, preservação e disponibilização desses arquivos não pode estar sujeita a critérios conjunturais, arbitrários e provisórios. Assim é fundamental salvaguardar os arquivos apoiando-se em normas básicas e não em critérios conjunturais que comprometam o acesso e que signifiquem cerceamento de outros direitos. 
Os arquivos e seus documentos são definidos por Nazar (2014) como fontes possíveis para a história e para a memória da instituição que os gerou e como subsídios para a garantia do exercício de direitos. Para assegurar o exercício dessa tripla função é necessário que sejam observados princípios centrais da arquivística, a saber: os princípios de procedência, de ordenamento original, e de integridade dos documentos; e a avaliação dos documentos em conformidade com os distintos ciclos de vida, classificados como de primeira e segunda idade, quando tem valor primário, respectivamente administrativo e jurídico e de terceira idade, no qual tem valor secundário, histórico e alçam estado de vigência permanente.

A partir dessas delimitações Nazar (2007) classifica os documentos relativos à ditadura, adotando como princípio básico as instituições e organizações produtoras. A genealogia proposta distingue: arquivos da ditadura, cuja referência é um período histórico, de arquivos da repressão, que incluem fundos produzidos tanto por instituições repressivas ou vinculadas ao acionar repressivo, quanto por organizações que resistiram à ditadura.

\section{ARQUIVOS DA REPRESSÃO E DA RESISTÊNCIA}

Tomando como referência as classificações anteriores elaborei um quadro (QUADRO 2) indicando parte dos arquivos que pesquisei e sobre os quais apresentarei alguns resultados parciais.

Quadro 2 - Arquivos estatais e da sociedade civil

\begin{tabular}{|l|l|l|}
\hline Arquivos & \multicolumn{1}{|c|}{ Estatais } & \multicolumn{1}{|c|}{ Sociedade Civil } \\
\hline Brasil & $\begin{array}{l}\text { Arquivo Nacional- guarda fundo da CNV e do regime } \\
\text { militar }\end{array}$ & $\begin{array}{l}\text { Brasil Nunca } \\
\text { Mais }\end{array}$ \\
\hline Argentina & $\begin{array}{l}\text { Arquivo Nacional da Memória- guarda fundo CONADEP e } \\
\text { outros }\end{array}$ & Memoria Aberta \\
\hline
\end{tabular}

Fonte: elaboração própria (2016)

O Arquivo Nacional da Memória, da Argentina e o Arquivo Nacional, do Brasil, são as instituições de guarda e de disponibilização dos fundos documentais provenientes das comissões de verdade que atuaram nesses países, respectivamente 
entre 1983-1984 e 2011-2014. E o arquivo DIPBA é um fundo da polícia provincial de Buenos Aires, semelhante aos arquivos do DOPS no Brasil, durante a ditadura militar. Apresento a seguir uma breve descrição desses arquivos gerados no âmbito do Estado

O Arquivo Nacional da Memória foi criado em 2003 (Decreto Nacional 1.259/2003) e está vinculado ao Ministério da Justiça, Segurança e Direitos humanos /Secretaria de Direitos Humanos. O Fundo CONADEP está sob a guarda do Arquivo Nacional da Memória, desde a criação do mesmo em 2003. Esse fundo é constituído por documentação resultante do trabalho da Comissão Nacional sobre Desaparecimentos (CONADEP). O acervo formado ao longo do trabalho da CONADEP incluiu tanto documentos produzidos pela própria comissão - durante a realização de atividades de coleta de testemunhos e visitas a centros clandestinos de detenção- quanto documentos provenientes de diversas organizações de direitos humanos, nacionais e internacionais, que durante a vigência do regime militar haviam registrado denúncias de desaparições, como a Assembleia Popular de Direitos Humanos (APDH), as Mães da Praça de Maio e a Comissão Interamericana de Direitos Humanos.

O Arquivo DIPBA foi constituído no rol de atividades da Polícia Política da Província de Buenos Aires e passou para a guarda da Comissão Provincial da Memória, desde a sua criação em 2000. A potencialidade e especificidade desse arquivo foi manter a mesma ordenação estabelecida pela instituição produtora. $O$ respeito a esses princípios de integralidade, ordem e proveniência, possibilita uma compreensão aprofundada de como operavam a polícia política provincial e os outros órgãos pertencentes ao aparato repressivo policial-militar, principalmente após a ditadura instaurada em 1976.

O Arquivo Nacional (AN), do Brasil, foi criado em 1838. Atualmente é vinculado ao Ministério da Justiça e atua como o principal órgão de implementação e de acompanhamento da política nacional. O arquivo é a instituição responsável pela guarda dos arquivos do regime militar e da Comissão Nacional da Verdade. O acervo da Comissão Nacional da Verdade é formado por

"documentos e material audiovisual recebidos por órgãos de governo, comissões da verdade estaduais, municipais e universitárias e de entidades de classe, pesquisados pela CNV em arquivos públicos e particulares, recebidos de depoentes, familiares de vítimas, de entidades da sociedade 
civil, assim como por documentos produzidos pela própria comissão. " (BRASIL, 2015, não p.)

Os fundos documentais produzidos por instituições do regime militar e seu aparato repressivo começaram a ser recolhidos ao Arquivo Nacional em 2005, a partir da formação de um grupo de trabalho organizado para essa finalidade, criado pela Secretaria Especial de Direitos Humanos da Presidência da República (Portaria no 21, de 21/02/05). O Ministério da Justiça emitia ofícios aos diversos órgãos dos três poderes e das forças armadas. O primeiro acervo importante recolhido foi o do Serviço Nacional Informações, em 2005. Em 2007 foram obtidos recursos financeiros essenciais ao projeto de recolhimento e disponibilização de documentos do regime militar (Projeto Memórias Reveladas) através de uma lei denominada Lei Rouanet destinada a obtenção de recursos para a área cultural. Com esses recursos foi possível

o tratamento dos acervos dos extintos Departamento Estadual de Ordem Política e Social (DEOPS) e Departamento de Ordem Política e Social (DOPS), órgãos centrais no aparato repressor do regime militar, que tinham como missão espionar e reprimir opositores. (BRASIL, 200?, não p.)

Esclareço que as condições de formação dos arquivos nacionais da Argentina e no Brasil foram distintas e que o Argentina também possui um Arquivo Geral que guarda importantes fundos que não foram objeto dessa investigação

Bom quanto aos arquivos provenientes de iniciativas da sociedade civil apresento para vocês duas inciativas, entre as muitas existentes em ambos os países: o Memoria Aberta (Argentina) e o Brasil Nunca Mais (Brasil).

O Arquivo Memória Aberta foi criado em 1999 por iniciativa de um conjunto de organizações de direitos humanos: Assembleia popular de direitos humanos (APDH), Centro de estudos legislativos (CELS), Madres Linha Fundadora, Fundação Memória Histórica e Justiça e Paz. A sua criação foi motivada para reunir, recuperar e disponibilizar materiais e documentos e criar novas fontes sobre a repressão na Argentina, conforme mencionado no site da instituição:

La apuesta inicial de Memoria Abierta fue reunir material disperso, recuperar documentación deteriorada y organizarla para el acceso público, crear nuevas fuentes registrando testimonios orales de protagonistas y testigos, y profundizar la investigación sobre el despliegue del plan de represión ilegal en el territorio nacional a través de la identificación y estudio de los numerosos edificios y sitios en los que pueden hallarse huellas del período (MEMORIA ABIERTA, 2011, não p.) 
A organização está dividida em três áreas com funções e características específicas: patrimônio documental, arquivo oral e topografia da memória.

A área de patrimônio documental tem como funções principais: a) organizar, classificar e descrever o acervo documental das organizações de direitos humanos pertencentes ao arquivo e b) estruturar, atualizar e disponibilizar essas informações em uma base de dados. Os documentos continuam sobre a guarda das instituições de origem e para consulta-los é necessário demanda-los em cada instituição. O que o arquivo propicia é o acesso a uma base de dados que possibilita consultas por diversas categoriais: nomes de pessoas, países, organizações, dentre outras.

O arquivo oral abriga principalmente uma ampla e bem elaborada coleção de vídeos com testemunhos, produzidos e gravados por sua equipe. A concepção e metodologia de trabalho detalhada desse arquivo oral está disponível em um manual. A terceira área, de Topografia da Memória destina-se a construir uma base de dados pública sobre centros clandestinos de detenção e outros espaços urbanos relacionados com o terrorismo de Estado.

No Brasil, em termos de constituição de arquivos da resistência um dos projetos mais relevantes é o "Projeto Brasil Nunca Mais", por ter resgatado as primeiras informações relativas às violações de direitos humanos cometidas pelo regime militar ainda em plena vigência do regime, em 1979. O projeto foi uma iniciativa da Arquidiocese de São Paulo (sob a direção do Cardeal Paulo Evaristo Arns) com o apoio do Conselho Mundial de Igrejas e arquivou:

Cópias de 707 processos políticos que transitaram pela Justiça Militar brasileira entre abril de 1964 e março de 1979, especialmente aqueles que atingiram a esfera do Supremo Tribunal Militar. As copias em microfilme foram feitas de duas vias, para que uma pudesse ser guardada, sem riscos, fora do país. (ARQUIDIOCESE DE SÃO PAULO, 1985, p. 22).

Do referido projeto resultaram um relatório de cerca de 5.000 páginas e o livro Brasil Nunca Mais, nos quais constam detalhes sobre os processos judiciais e os procedimentos de tortura, bem como os nomes dos torturadores, dos mortos, dos desaparecidos e dos torturados. O livro teve ampla vendagem, com 40 edições. Todos os documentos do Brasil Nunca Mas estão, desde de 2013, integralmente disponíveis on-line e os documentos originais estão na Universidade de Campinas (Arquivo Edgar 
Leuenroth). ${ }^{5}$ Esse arquivo é fundamental para a justiça transicional e as políticas de memória pois subsidiou a formação de todos os outros fundos que o sucederam tanto aqueles de iniciativa de organizações de familiares, como de iniciativa estatal.

\section{JUSTIÇA TRANSICIONAL E PUBLICIZAÇÃO DE INFORMAÇÕES SOBRE MORTOS E DESAPARECIDOS NO BRASIL}

Um outro aspecto que gostaria de apresentar para vocês é sobre o processo de publicitação das informações sobre mortos e desaparecidos no Brasil. Eu gostaria que vocês observassem como, ao logo período democrático, foi se alterando o escopo/objeto das comissões e consequentemente as informações relativas às violações aos direitos humanos.

Quadro 3 - Violações aos direitos humanos por fontes não governamentais e governamentais.

\begin{tabular}{|c|c|c|}
\hline $\begin{array}{c}\text { Instituição/ } \\
\text { Organização }\end{array}$ & Escopo/objeto/fonte & Dados mortes/desaparecidos/violações \\
\hline $\begin{array}{l}\text { Arquidiocese e } \\
\text { CMI/Brasil } \\
\text { Nunca Mais- } \\
(1979-1985)\end{array}$ & $\begin{array}{lr}\text { Processos políticos que } \\
\text { tramitaram na Justiça } \\
\text { Militar entre } & 1964-79 . \\
\text { Processos 695. } & \\
\text { Tortura, } & \\
\text { repressivo, } & \end{array}$ & $\begin{array}{l}\text { Em } 695 \text { processos- } 7.367 \text { nomes } \\
\text { pessoas levadas a JM. Dados da prisão- } \\
\text { só em 3.975; destes } 1043 \text {, presos antes } \\
\text { do inquérito. } \\
\text { Tipo de acusação- maioria militância } \\
\text { organizações políticas- } 4.935 \text { casos. } \\
\text { Torturados- Declaração dos réus sobre } \\
\text { sofrimento de tortura no inquérito- } 1.918 \\
\text { pessoas. Desaparecidos- } 125\end{array}$ \\
\hline $\begin{array}{c}\text { Dossiê Mortos e } \\
\text { desaparecidos } \\
\text { políticos- } 1995 . \\
\text { Familiares }\end{array}$ & $\begin{array}{l}\text { Informações projeto Brasil } \\
\text { Nunca Mais; acervos IML } \\
\text { S.P, R.J e Pernambuco, } \\
\text { DOPS estaduais, } \\
\text { documentos privados de } \\
\text { militares e ex-presos } \\
\text { políticos. }\end{array}$ & Desaparecimentos e mortes - 339 casos. \\
\hline $\begin{array}{l}\text { Comissão } \\
\text { espacial sobre } \\
\text { Mortos e } \\
\text { desaparecidos } \\
\text { (CEMD) - Lei } \\
9.140 / 1995\end{array}$ & $\begin{array}{l}\text { Reconhecimento do } \\
\text { Estado brasileiro pelas } \\
\text { violações. } \\
\text { Relatório- } 2007\end{array}$ & $\begin{array}{l}\text { Lista inicial- } 136 \text { casos, deferidos } 221 \\
\text { casos; } \\
\text { Narrativa dos casos em ordem } \\
\text { cronológica, síntese do processo, } \\
\text { menção responsabilidades. }\end{array}$ \\
\hline
\end{tabular}

\footnotetext{
${ }^{5}$ Para história do projeto ver FIGUEIREDO (2009) e sobre arquivo digital BNM ver THIESEN e COITINHO(2014). Os arquivos estão disponíveis em http://bnmdigital.mpf.mp.br/\#!/
} 


\begin{tabular}{|c|c|c|}
\hline $\begin{array}{c}\text { Comissão de } \\
\text { Anistia- Lei } \\
\text { 10.559/2002 }\end{array}$ & $\begin{array}{l}\text { Disciplina condição de } \\
\text { anistiado político, prevista } \\
\text { na Constituição de } 1988 \text { e } \\
\text { prevê reparações para } \\
\text { atos de exceção, de } \\
\text { perseguição política- } \\
\text { prisões ilegais e arbitrárias, } \\
\text { tortura, demissões e } \\
\text { expurgos estudantis, } \\
\text { clandestinidade exílios } \\
\text { forçados. }\end{array}$ & $\begin{array}{l}\text { Até } 2014-62.000 \text { requerimentos, cerca } \\
\text { de } 35.000 \text { deferidos. }\end{array}$ \\
\hline $\begin{array}{l}\text { Comissão } \\
\text { Nacional da } \\
\text { Verdade- Lei } \\
12.528 / 2011\end{array}$ & 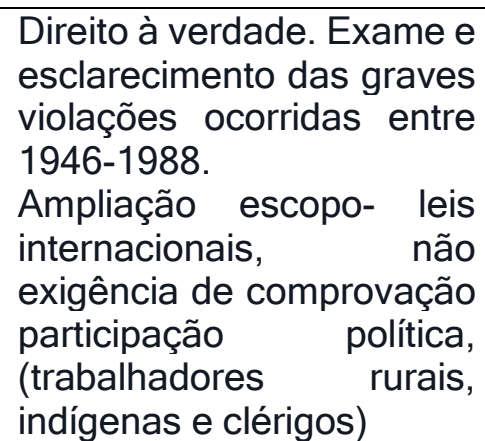 & $\begin{array}{l}\text { Relatório final-relatos sobre casos de } 191 \\
\text { mortos e } 243 \text { desaparecidos - desses } \\
\text { últimos, } 33 \text { foram identificados ao longo } \\
\text { das últimas décadas }\end{array}$ \\
\hline
\end{tabular}

Fonte: elaboração própria (2016)

Cabe mencionar que as informações sobre mortos e desaparecidos no Brasil foram publicizadas principalmente em função das lutas de pressões de organizações de familiares e de direitos humanos, mas também em virtude da ampliação da normativa nacional e internacional sobre direitos humanos e sobre o direito à informação, a verdade e a justiça.

\section{CONSIDERAÇÕES FINAIS}

No plano político e social penso que o acesso amplo à informação pública e a apropriação consciente dessas informações por uma cidadania ativa são elementos fundamentais para a construção do Estado democrático de direito, no Brasil e na Argentina.

No plano acadêmico destaco que essa extensa documentação e os testemunhos sobre as violações de direitos humanos, ocorridas durante os processos repressivos no Brasil e na Argentina, precisam ser objeto de estudo e de investigação para as nossas áreas de atuação a arquivologia, a biblioteconomia e a museologia. Essas áreas com certeza podem contribuir de maneira decisiva para os processos de 
organização, difusão, acesso e publicitação desses fundos tão importantes para a memória, a verdade e a justiça.

\section{REFERÊNCIAS}

ANDRADE, Ana Maria Cardoso de. Um novo texto no contexto da informação popular: os centros de documentação. São Paulo, 1989. 202 p. Tese (Doutorado em Ciências da Comunicação). Universidade de São Paulo, 1989.

ABRÃO, Paulo; GENRO, Tarso. Os direitos da transição e a democracia no Brasil. Belo Horizonte: Fórum, 2012.

ARENDT, Hanna. Entre o passado e o futuro. 5. Ed. São Paulo: Perspectiva. 1979.

Eischmann em Jerusalém: um relato sobre a banalidade do mal. São Paulo: Companhia das letras, 1999.

ARGENTINA. CONADEP. Informe de la Comisión Nacional sobre la Desaparición de Personas. Buenos Aires: Eudeba, 2014.

ARQUIDIOCESE DE SÃO PAULO. CONSELHO MUNDIAL DE IGREJAS. Brasil Nunca Mais. Petrópolis: Vozes, 1985.

BRASIL. COMISSÃO NACIONAL DA VERDADE. Relatório da Comissão Nacional da Verdade. Brasília: CNV, 2014. Disponível em:< http://www.cnv.gov.br/>. Acesso em: 08 dez. 2016.

BESSE, Juan; ESCOLAR, Cora. Políticas y memoria, semblanza de una relación indócil. Diálogos, Revista do departamento de história, Maringá, v.16, n. 3, p. 897 924, set./dez.2012. Disponível em: <

http://www.redalyc.org/pdf/3055/305526887004.pdf> Acesso em: 08 dez. 2016.

BRITO, Alexandra. Truth, justice, memory and democratization in the Southern Cone. In: BRITO, Alexandra; GONZALÉZ-ENRÍQUE, Carmen; AGUILAR, Paloma. The politics of memory: transitional justice in democratizing societies. London: Oxford University Press. 2002.

CRENZEL, Emílo. La historia política del nunca más. Buenos Aires: Siglo veintiuno, 2014.

COMISSIÓN PROVINCIAL POR LA MEMORIA. Arquivo dipba. La Plata: COM, 2005. Disponível em:

<http://www.comisionporlamemoria.org/cuadroclasificacion/\#seccion12>. Acesso em: 08 dez. 2016. 
FELD, Claudia; FRANCO, Marina. Democracia, hora cero: actores, políticas y debates em los incios de la posdictadura. Buenos Aires: Fondo de Cultura económica, 2015.

FROTA, Maria Guiomar da Cunha. Comissão da Verdade e Lei de Acesso à Informação: informação, memória e justiça no contexto democrático pós-1988. In: MOURA, Maria Aparecida (org). A construção do acesso público à informação no Brasil, Belo Horizonte: UFMG, 2014.

JELIN, Elizabeth. Los trabajos de la memoria. Madrid: Siglo veintiuno, 2002.

KARABABIKIAN, Graciela. Archivos y derechos humanos en Argentina. Buenos Aires: Memoria Abierta, 200?. Disponível em:

$<$ http://www.memoriaabierta.org.ar/materiales/pdf/archivos y derechos humanos.pd f>. Acesso em: 08 dez 2016.

MEMORIA ABIERTA. Memória aberta. Caba: Memoria aberta, 2015. Disponível em: <http://www. memoriaabierta.org.ar>. Acesso em: 08 dez. 2016.

MOURA, Maria Aparecida (org). A construção do acesso público à informação no Brasil. Belo Horizonte: UFMG, 2014.

NAZAR, Mariana. Dictadura, archivos y accesibilidad documental: a modo de agenda. In: CENTRO DE ESTUDOS LEGALES Y SOCIALES. Derechos humanos en la Argentina: informe 2007. Madrid: Siglo veintiuno, 2007.

NAZAR, Mariana. El acceso a los archivos: sistemas de gestión de la información implementados en América Latina. In: TORRES, Natália (comp.) Hacia una política integral de gestión de la información pública. Buenos Aires: Universidad de Palermo, 2014.

RABOTNIKOF, Nora. Memoria política a treinta años del golpe. In: LIDA, Clara; CRESPO, Horacio; YANLEVICH, Pablo (comp.). Argentina, 1976: estudios em torno el golpe de estado. México: El Colégio de México, 2006.

TORELLY, Marcelo D. Justiça de transição e estado constitucional de direito: perspectiva teórico comparada e análise do caso brasileiro. Belo Horizonte: Fórum, 2012.

THIESEN, Icléia. Documentos sensíveis. Rio de Janeiro: 7letras, 2014.

THIESEN, Icléia. Memória Institucional. João pessoas: UFBA, 2013. 